\title{
Editorials
}

\section{Innovative techniques to enhance lung preservation}

Richard J. Novick, MD

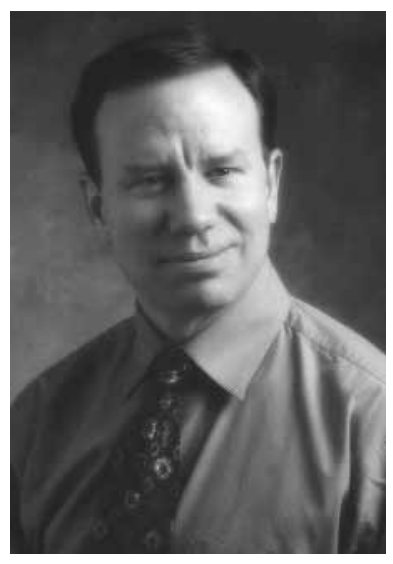

See related article on page 98 .
From the Department of Cardiac Surgery, London Health Science Center, London, Ontario, Canada.

Received for publication Aug 7, 2001; accepted for publication Sept 13, 2001

Address for reprints: Richard J. Novick, MD, Chief, Division of Cardiac Surgery, London Health Science Center, Room D228, NR SSC Satellite Office, London, Ontario N6A 4G5, Canada.

J Thorac Cardiovasc Surg 2002;123:3-5

Copyright (C) 2002 by The American Association for Thoracic Surgery

$0022-5223 / 2002 \$ 35.00+0 \quad \mathbf{1 2 / 1 / 1 2 0 3 3 1}$

doi:10.1067/mtc.2002.120331

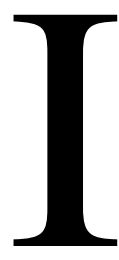

this issue of the Journal, Strüber and associates ${ }^{1}$ report the results of a series of experiments comparing the effect of retrograde versus antegrade perfusion of lung grafts on oxygenation, compliance, and surfactant function in a porcine model. The Hannover group has a venerable track record of conducting innovative research in lung preservation and was the first to report the use of exogenous surfactant therapy to treat ischemia-reperfusion injury after clinical lung transplantation. ${ }^{2}$ The current article will add to the burgeoning field of research on new methods of lung preservation designed to decrease post-transplant graft dysfunction and potentially enlarge the donor pool.

\section{Lung Preservation as a Rate-limiting Step to Lung Transplantation}

A shortage of suitable lung grafts has been a major rate-limiting step in clinical lung transplantation during the past decade. The majority of prospective donor lungs exhibit hypoxemia and pulmonary infiltrates due to edema, aspiration, and pneumonia associated with the effects of brain death and the need for ventilatory support in organ donors. ${ }^{3}$ Recent work has confirmed that some lung grafts previously deemed unsuitable can in fact be transplanted successfully. ${ }^{4}$ Nevertheless, most such grafts will still be too compromised to permit successful harvesting for transplantation. New methods to rescue these grafts or mitigate ischemia-reperfusion injury after transplantation will go a long way toward reducing the supply-demand imbalance that currently plagues clinical lung transplantation.

\section{Pulmonary Surfactant and Lung Preservation}

An interesting feature of Strüber and associates' article is a study of the impact of different techniques of lung graft flushing on the pulmonary surfactant system. Surfactant is a lipid-protein complex produced by type II pneumocytes, which stabilizes the lung by reducing surface tension at the alveolar-pulmonary capillary interface. ${ }^{5}$ Surfactant recovered by bronchoalveolar lavage consists of subfractions differing in morphologic appearance and buoyant density. The heavy subtype or surfactant large aggregate fraction, which contains lamellar bodies, tubular myelin, and large vesicles, is rich in the surfactant proteins SP-A, SP-B, and SP-C and is highly surface active. The light subtype or small aggregate subfraction, consisting of small vesicles, contains less surfactant protein and has poor surface activity., ${ }^{5,6}$ 1991, my colleagues and $\mathrm{I}^{5}$ reviewed the laboratory work that was performed between 1965 and 1974 characterizing alterations in the surface activity of surfactant after lung reimplantation and allografting in dogs. Our laboratory subsequently reported that lung transplantation in dogs after a 12-hour period of cold ischemia and a 6-hour period of reperfusion was associated with increased total serum protein in lung lavage, an increased small aggregate/large aggregate (SA/LA) ratio, increased sphingomyelin, and decreased phosphatidylglycerol concentrations in large aggregates and a decreased SP-A content. ${ }^{7}$ These alterations in surfactant resembled those observed in many injuries resembling adult respiratory distress syndrome. ${ }^{8}$ Further studies in rats supported these findings ${ }^{9,10}$; the latter study cor- 
related the severity of ischemia-reperfusion injury with the amount of tubular myelin in the lungs on stereologic analysis. ${ }^{10}$ The Hannover group confirmed in 1998 that pulmonary surfactant activity was impaired clinically in lung transplant recipients. ${ }^{11}$ Further experimental work by Strüber and his associates ${ }^{12}$ showed that lung flushing with low-potassium dextran (LPD) solution was associated with a lower SA/LA ratio and better surfactant function than Euro-Collins solution in a porcine model of 90 minutes of warm ischemia.

\section{Retrograde Versus Antegrade Lung Flushing for Preservation}

In the article in this month's Journal, the Hannover group focused on whether the use of retrograde, as opposed to antegrade, lung flushing with LPD solution would produce better oxygenation, lung compliance, and surfactant function after 24 hours of cold ischemia. Administration of pulmonary flush solution via the retrograde route has been explored since the early 1990s as an alternative technique to overcome some of the limitations associated with antegrade flushing methods. ${ }^{13-18}$ One of the postulated advantages of the retrograde technique includes a lower vascular resistance during flushing on the pulmonary venous as opposed to the pulmonary arterial side. In addition, it has been proposed that flush solutions delivered retrogradely through the left atrium could perfuse both the bronchial and pulmonary circulations, thus theoretically enhancing pulmonary parenchymal and airway preservation ${ }^{13}$; subsequent work, however, has cast doubt on this hypothesis. ${ }^{17}$ In the current article, Strüber and associates showed that retrograde flushing with LPD solution resulted in significantly better oxygenation and compliance in transplanted lungs than antegrade flushing. However, the results with respect to surfactant function and aggregate forms were equivocal. Unfortunately, the second and final bronchoalveolar lavage for surfactant analysis was carried out after only 2 hours of reperfusion, whereas its performance at the end of the experiment (ie, after 7 hours of reperfusion) would have produced more meaningful results. Furthermore, the measurement of levels of SP-A in bronchoalveolar lavage samples would have significantly strengthened this article, since lung preservation is associated with decreased SP-A levels in other models. ${ }^{7}$ The authors did show, however, that retrograde lung flushing was associated with a significantly lower SA/LA ratio at 2 hours of reperfusion than antegrade flushing, although surface tension in the antegrade and retrograde groups increased to a similar degree. They concluded that although retrograde lung flushing led to better initial graft function than the standard antegrade perfusion technique, surfactant dysfunction was present in both groups. This latter finding was consistent with the results of studies by Chen and asso- ciates, ${ }^{15}$ who demonstrated that the contents of lamellar bodies of type II pneumocytes (that contain surfactant) were reduced after retrograde flushing, despite excellent preservation of oxygenation and lung compliance after 24 hours of preservation.

\section{Possible Role of Exogenous Surfactant Therapy in Lung Preservation}

The observation that lung preservation results in adverse alterations in the endogenous surfactant system resulted in our suggestion in 1991 that exogenous surfactant therapy be explored as a "future tool of the lung transplant surgeon." Exogenous surfactant therapy has been investigated for some time as a possible treatment of various types of severe acute lung injury. ${ }^{8}$ Key issues that need to be considered in the potential application of this treatment modality include the type of exogenous surfactant used, its delivery technique (ie, instilled versus aerosolized), and the timing of its administration (ie, to donors, recipients, or both). Furthermore, ventilatory strategies subsequent to its administration could have a profound impact on both the endogenous and exogenous surfactant pools. ${ }^{6,19}$

Work in our laboratory in 1996 showed that in normal canine lungs treatment of donors with exogenous surfactant before hypothermic graft storage for 36 hours was associated with less severe lung injury after reperfusion than recipient therapy alone. ${ }^{20}$ Furthermore, combined donor aerosol and recipient instilled surfactant therapy was associated with a superior physiologic response during reperfusion and an increased recovery of aerosolized and instilled exogenous surfactant, compared with either modality of exogenous surfactant treatment alone. In a subsequent study, a canine model of the compromised lung donor was created via 8 hours of high-volume ventilation. ${ }^{21}$ Administration of instilled bovine lipid extract surfactant to donor lungs in this model reduced protein leak, maintained a low surfactant SA/LA ratio, and resulted in better oxygenation after transplantation than that of untreated grafts. ${ }^{21}$ Further experimental work has shown that the exogenous instilled surfactant did not equilibrate completely with the endogenous surfactant pool in this model, despite being in the transplanted lungs for 30 hours. ${ }^{6}$

Experience with exogenous surfactant therapy in the setting of clinical lung transplantation has, to date, been limited. To our knowledge, no clinical report on the administration of exogenous surfactant to lung donors has been published. Strüber and associates ${ }^{2}$ were the first to document the successful clinical treatment of a lung transplant recipient with established ischemia-reperfusion injury with nebulized synthetic surfactant in 1995. Subsequent review of their clinical experience with graft dysfunction after lung transplantation demonstrated the successful treatment of 6 consecutive patients with severe ischemia-reper- 
fusion injury with the same nebulized exogenous surfactant preparation. ${ }^{22}$ The ability of the chosen therapy to consistently mitigate ischemia-reperfusion injury was surprising, because the surfactant preparation lacked SP-A, which has been shown experimentally to be important in resisting inhibition of surfactant by serum protein in the airways. 5,23 Moreover, nebulized exogenous surfactant would have been expected to localize in better ventilated (ie, less injured) areas of the lungs, rather than in those with suboptimal ventilation resulting from ongoing ischemia-reperfusion injury.

\section{Summary}

The above experiences indicate that exogenous surfactant therapy is a potentially promising therapy to mitigate severe pulmonary ischemia-reperfusion injury, but more research needs to be done to determine the optimal surfactant preparation and mode of therapy in the clinical setting. In addition, the time has come to formally evaluate retrograde versus antegrade flushing techniques in clinical lung transplantation. This requires an appropriately powered (likely multi-institutional) randomized controlled trial, with welldefined, a priori, primary and secondary end points. Furthermore, the ability of exogenous surfactant therapy, retrograde lung flushing, and other new techniques to rescue donor lung grafts that have been subject to various forms of experimentally induced injury should be studied further in the laboratory to determine the potential future use of these treatment modalities in the clinical arena to expand the pool of donor lungs.

\section{References}

1. Strüber M, Hohlfeld JM, Kofidis T, Warnecke G, Neidermeyer J, Sommer SP, et al. Surfactant function in lung transplantation after 24 hours ischemia: advantage of retrograde flush perfusion for preservation. J Thorac Cardiovasc Surg. 2002;123:98-103.

2. Strüber M, Cremer J, Harringer W, Hirt SW, Costard-Jackle A, Haverich A. Nebulized synthetic surfactant in reperfusion injury after single lung transplantation. J Thorac Cardiovasc Surg. 1995;110:563-4.

3. Novick RJ, Gehman KE, Ali IS, Lee J. Lung preservation: the importance of endothelial and alveolar type II cell integrity. Ann Thorac Surg. 1996;62:302-14.

4. Sundaresan S, Semenkovich J, Ochoa L, Richardson G, Trulock EP, Cooper JD, et al. Successful outcome of lung transplantation is not compromised by the use of marginal donor lungs. J Thorac Cardiovasc Surg. 1995;109:1075-9.

5. Novick RJ, Possmayer F, Veldhuizen RAW, Menkis AH, McKenzie FN. Surfactant analysis and replacement therapy: A future tool of the lung transplant surgeon? Ann Thorac Surg. 1991;52:1194-200.
6. Maitra G, Inchley K, Novick RJ, Veldhuizen RAW, Lewis JF, Possmayer F. Acute lung injury and lung transplantation influence in vitro subtype conversion of pulmonary surfactant. Am J Physiol Lung Cell Mol Physiol. In press.

7. Veldhuizen RAW, Lee J, Sandler D, Hull W, Whitsett JA, Lewis J, et al. Alterations in pulmonary surfactant composition and activity after experimental lung transplantation. Am Rev Respir Dis. 1993;148:208-15.

8. Lewis JF, Jobe AH. Surfactant and the adult respiratory distress syndrome. Am Rev Respir Dis. 1993;147:218-33.

9. Andrade RS, Solien EE, Wangensteen OD, Tsai MY, Kshettry VR, Bolman RM. Surfactant dysfunction in lung preservation. Transplantation. 1995;60:536-41.

10. Ochs M, Fehrenbach H, Nenadic I, Bando T, Fehrenbach A, Schepelmann D, et al. Preservation of intraalveolar surfactant in a rat lung ischemia/reperfusion injury model. Eur Respir J. 2000;15:526-31.

11. Hohlfeld JM, Tiryaki E, Hamm H, Hoymann HG, Krug N, Haverich A, et al. Surfactant pulmonary activity is impaired in lung transplant recipients. Am J Respir Crit Care Med. 1998;158:706-12.

12. Strüber M, Hohlfeld JM, Fraund S, Kim P, Warnecke G, Haverich A. Low-potassium dextran solution ameliorates reperfusion injury of the lung and protects surfactant function. J Thorac Cardiovasc Surg. 2000;120:566-72.

13. Sarsam MA, Yonan NA, Deiraniya AK, Rahman AN. Retrograde pulmonaryplegia for lung preservation in clinical transplantation: a new technique. J Heart Lung Transplant. 1993;12:494-8.

14. Chen CZ, Gallagher RC, Ardery P, Dyckman W, Low HB. Retrograde versus antegrade flush in canine left lung preservation for six hours. $J$ Heart Lung Transplant. 1996;15:395-403.

15. Chen CZ, Gallagher RC, Ardery P, Dyckman W, Donabue S, Low HB. Retrograde flush and cold storage for twenty-two to twenty-five hours lung preservation with and without prostaglandin $\mathrm{E}_{1}$. J Heart Lung Transplant. 1997;16:658-66.

16. Varela A, Cordoba M, Serrano-Fiz S, Burgos R, Montero CG, Tellez G, et al. Early lung allograft function after retrograde and antegrade preservation. J Thorac Cardiovasc Surg. 1997;114:1119-20.

17. Bitu-Moreno J, Francischetti I, Siemer R, Matheis G, Baretti R, Maffei FH, et al. Influence of different routes of flush perfusion on the distribution of lung preservation solutions in parenchyma and airways. Eur J Cardiothorac Surg. 1999;15:481-9.

18. Venuta F, Rendina EA, Bufi M, Della Rocca G, De Giacomo T, Costa MG, et al. Preimplantation retrograde pneumoplegia in clinical lung transplantation. J Thorac Cardiovasc Surg. 1999;118:107-14.

19. Ito Y, Veldhuizen RAW, Yao LJ, McCaig LA, Bartlett AJ, Lewis JF. Ventilation strategies affect surfactant aggregate conversion in acute lung injury. Am J Respir Crit Care Med. 1997;155:493-9.

20. Novick RJ, MacDonald J, Possmayer F, Wan F, Duplan J, Denning L, et al. Evaluation of surfactant treatment strategies after prolonged graft storage in lung transplantation. Am J Respir Crit Care Med. 1996;154:98-104.

21. Novick RJ, Gilpin AA, Gehman KE, Ali IS, Veldhuizen RA, Duplan $\mathrm{J}$, et al. Mitigation of injury in canine lung grafts by exogenous surfactant therapy. J Thorac Cardiovasc Surg. 1997;113:342-53.

22. Strüber M, Hirt SW, Cremer J, Harringer W, Haverich A. Surfactant replacement in reperfusion injury after clinical lung transplantation. Intensive Care Med. 1999;25:862-4.

23. Cockshutt AM, Weitz J, Possmayer F. Pulmonary surfactant-associated protein $\mathrm{A}$ enhances the surface activity of lipid extract surfactant and reverses inhibition by blood proteins in vitro. Biochemistry. 1990;29:8424-9. 